B Research S Suare

\title{
A health and food-system analysis of Brexit-related policy approaches
}

Florian Freund

Thuenen Institute

Marco Springmann ( $\square$ marco.springmann@ndph.ox.ac.uk)

University of Oxford https://orcid.org/0000-0001-6028-5712

\section{Article}

Keywords: Brexit, food systems, diet-related mortality

Posted Date: January 12th, 2021

DOl: https://doi.org/10.21203/rs.3.rs-128413/v1

License: (a) (i) This work is licensed under a Creative Commons Attribution 4.0 International License. Read Full License

Version of Record: A version of this preprint was published at Nature Food on June 28th, 2021. See the published version at https://doi.org/10.1038/s43016-021-00306-9. 


\section{Abstract}

Brexit is expected to have significant impacts on the UK food system, which has implications for dietary risk factors and public health. Here we use an integrated economic-health modelling framework to analyse the impacts of different policy approaches to Brexit. According to our analysis, a "Hard Brexit" could increase diet-related mortality in the UK as costs for health-promoting and import-dependent foods, such as fruits and vegetables, increase and their consumption decreases. Negotiating free-trade agreements with the USA and Commonwealth countries as part of a "Global Britain" approach led to relative increases in food availability, but not of health-promoting foods, resulting in further increases in diet and weight-related mortality. Negotiating a free-trade agreement with the EU addressed both food availability and fruit and vegetable intake, which halved the increases in mortality. Combining this "Soft Brexit" approach with an agricultural subsidy reform that incentivises greater production of fruits and vegetables mitigated the Brexit-related increases in risk factors and led to net improvements in dietrelated mortality.

\section{Introduction}

The UK's exit from the European Union (EU) on 31 January 2020 has sparked intense discussions on the future relationship between the UK and the EU on the one hand, and the UK and other potential trading partners on the other. At the same time, domestic policies intended to replace those of the EU are being drafted, including a new agricultural bill set to replace the EU's Common Agricultural Policy. Withdrawing from EU institutions and regulations can be expected to lead to changes across all sectors of the British economy ${ }^{1,2}$, and will have implications for public and private life in the UK and Europe.

Here we focus on the impact the British withdrawal from the EU could have on the food supply in the UK ${ }^{3}$ and its implications for diets and diet-related health. Currently about one half of all food consumed in the UK, by value, is produced domestically, $30 \%$ is imported from the EU, and $20 \%$ imported from countries outside of the EU ${ }^{4}$. For particular commodities, the import dependence can be considerable higher. For example, more than three quarters of fruits and vegetables consumed in the UK are imported ${ }^{4}$. At the same time, dietary risks, including low consumption of fruits and vegetables and high consumption of red and processed meat, are the second biggest risk factor for mortality in the UK, after tobacco ${ }^{5}$. Any changes in the trade and regulatory regime between the UK on the one side, and the EU and its partners on the other side, will pose serious challenges to the British food system that will have consequences not only for agricultural trade and production, but also for dietary risks and diet-related health in the UK 6,7 .

Here we use a coupled economic-health modelling framework to provide a comprehensive analysis of Brexit-related policy approaches and their potential impacts on the food system and dietary health in the UK (Methods). Our point of departure is the UK's default position, sometimes referred to as "Hard Brexit". In that scenario, the UK loses preferential access to the EU's market and to most countries the EU has trade agreements with. Trade is governed by conditions set out by the World Trade Organization (WTO), including mutual tariffs and non-tariff measures that, for example, are associated with customs checks 
and divergences of regulation and standards. Policy responses to a "Hard Brexit" range from international ones involving new trade agreements to domestic ones involving national policy reforms. We constructed three policy scenarios, and combinations of those, to represent current policy initiatives and discussions.

With respect to trade-related responses, we differentiated between a "Global Britain" approach in which new trade agreements are sought with the USA and Commonwealth countries, and a "Soft Brexit" approach which focusses on creating a free-trade agreement with the EU. Tariffs between trading partners are eliminated in each scenario, and non-tariff measures are reduced but not completely eliminated.

With respect to domestic policy responses, we focused on an intended reform of agricultural subsidies as part of a "Taking back control" approach. Changes to agricultural subsidies that so far have been governed by the EU's Common Agricultural Policy could have major implications for the UK food system, which makes a step-wise introduction of new measures likely. In line with a "public money for public goods" intention, we constructed a scenario in which a quarter of subsidies are directed towards the production of food commodities with beneficial health and environmental characteristics. For our scenario, we chose horticultural products, including fruits, vegetables, legumes, and nuts as eligible for such subsidies. This choice is in line with environmental and health assessments of foods ${ }^{8-10}$, and with an aim of mitigating the potential health impacts Brexit could have on health-promoting and tradeexposed food groups ${ }^{7}$.

The different Brexit-related policies and scenarios are not mutually exclusive. For example, a subsidy reform as part of a "Taking back control" approach can be pursued alongside a free-trade agreement with the EU as part of a "Soft Brexit" approach. However, in practice, each policy will have a different time horizon. We therefore first analyse each policy's impact on the food system and health in isolation, and then consider different policy combinations. The latter is meant to provide information on which policies are suitable for being part of a health-sensitive food-policy mix post Brexit.

We used a coupled economic-health modelling framework to analyse the different policy approaches to Brexit. In the economic analysis, we used a computable general equilibrium model with agricultural detail, the Modular Applied General Equilibrium Tool (MAGNET) ${ }^{11}$, to estimate the potential impacts that changes in trade costs could have on agricultural trade, production and consumption in the UK. The model combines economic theory and empirical data according to which relative prices of commodities adjust so that supply matches demand across different sectors and regions. Due to its structure, the models allow for the identification of causal effects of policy experiments and other external factors on parameters, such as economic output per sector, inter-regional trade, and national consumption.

We paired the outputs of the economic analysis with a national risk-disease model to estimate the impacts that dietary changes related to Brexit could have on disease mortality in the UK. The risk-disease model was based on the concept of comparative risk assessment which is used regularly by the Global Burden of Disease project and relates changes in risk factors, such as reductions in fruit and vegetables, 
to changes in cause-specific mortality, such as cancer and coronary heart disease ${ }^{12,13}$. Our UK-based model included eight diet and weight-related risk factors and five disease endpoints, and it was parameterised with country and age-specific data on mortality, population, and body weight ${ }^{14,15}$. We used the model to estimate Brexit-related changes in the diet-related disease burden in the UK expressed as attributable deaths.

We begin our analysis with an exposition of the UK's trade position, followed by a description of the impacts the different policy options had on trade and domestic production. We then detail the impacts on food consumption and the health burden of diet-related diseases.

\section{The UK's food trade}

Before the UK's exit from the EU, the UK was highly dependent on food imports, most of which were coming from the EU (Table 1). In 2019, the value of imports was especially high for horticultural products such as vegetables, fruits, roots and legumes (USD 9.5 billion), followed by dairy (USD 4.1 billion) and other animal products such as poultry (USD 3.8 billion) and pork (USD 3.0 billion). The value of imports from the EU constituted about half of the value of all imports for the category of vegetables, fruits, roots, and legumes, and above $80 \%$ for the case of pork and poultry. The export values were generally smaller, with dairy having the greatest value (USD 2.4 billion), two thirds of which went to the EU. The selfsufficiency ratio, which indicates how much consumer demand is met by domestic production, was high for sheep and goat meat (108\%) part of which is produced for export, dairy products (86\%), and wheat and other grains (82-89\%). Self-sufficiency was low for horticultural products such as vegetables, fruits, roots and legumes $(24 \%)$ and rice $(16 \%)$.

After Brexit, trade is governed either by new trade agreements or by conditions set out by the World Trade Organization (WTO). Based on the WTO conditions, the UK has issued global tariff lines which will apply to imports from countries with no mutual trade agreement (Table 1). The tariffs are especially high for sheep and lamb meat (47\%), beef (42\%), dairy (33\%), and sugar (31\%), but still significant for other commodities such as wheat (17\%), poultry $(17 \%)$, pork $(14 \%)$, and horticultural products $(11 \%)$. In addition, non-tariff measures associated with customs checks and divergences of regulation and standards are expected to apply (Table 1). New trade agreements are assumed to reduce tariff lines to zero and non-tariff measures by two thirds due to greater regulatory alignment ${ }^{16}$.

\section{The impacts of Brexit policies on food trade and production}

In our analysis, the changes in trade costs from the imposition of UK's global tariffs and new non-tariff measures under a "Hard Brexit" has a large influence on agricultural trade and production (Figure 1a). Imports declined by about two thirds for dairy $(-69 \%)$ and beef $(-60 \%)$, by a third for pork $(-33 \%)$ and wheat $(-35 \%)$, and by about a tenth for sugar $(-15 \%)$, other grains $(-12 \%)$, vegetable oils $(-10 \%)$, and horticultural products $(-10 \%)$. Changes in exports and production mitigated some of the declines in imports. Exports decreased by $70 \%$ or more for beef (-95\%), dairy (-72\%), and pork (-72\%), whilst production increased by $6 \%, 16 \%$, and $22 \%$ for the same commodities. 
Negotiating global trade deals with the USA and Commonwealth countries as part of a "Global Britain" approach mitigated some of the Brexit-related reductions in trade (Figure 1b). Imports did not decline as strongly as in the "Hard Brexit" scenario, especially for wheat (-4\%) and pork (-5\%). Instead of decreasing, beef imports increased (7\%), displacing domestic production (-5\%). Dairy imports still showed large reductions $(-50 \%)$, which were accompanied by increases in domestic production (10\%).

Implementing a free-trade agreement with the EU also had a mitigating effect on the Brexit-related reductions in trade (Figure 1c). For most commodities, it reduced the changes in trade and production that would be associated with a Hard Brexit by more than half. Compared to the "Global Britain" approach, it led to greater mitigation of the negative trade effects related to Brexit, except for the imports and exports of beef $(-20 \%$ for imports, $-37 \%$ for exports), dairy $(-19 \%,-26 \%)$, wheat $(-13 \%,-28 \%)$, and pork $(-13 \%,-31 \%)$, which still showed significant reductions.

A reform of agricultural subsidies as part of a "Taking back control" approach had a particularly large impact on the newly supported types of food (Figure 1d), which in our model scenario were horticultural products. In our analysis, the production of horticultural products increased significantly (18\%), replacing grains $(-6 \%)$, sugar $(-4 \%)$, and oil crops (-18\%). Compared to the "Hard Brexit" scenario, exports of horticultural products decreased less drastically (-23\% compared to $-42 \%)$. However, changes in imports and the trade position of other agricultural commodities stayed similar.

Combining the different policies lessened the Brexit-related reductions in trade (Figure S1). Instead of showing reductions, imports of beef $(+29 \%)$, pork $(+6 \%)$, and wheat $(+10 \%)$ increased when global and EU trade deals were combined, and dairy imports decreased less drastically $(-10 \%)$ than in the individual policy scenarios, which triggered less production feedback. Adding agricultural subsidy reform to the mix increased the domestic production of horticultural products, without significantly impacting other sectors.

\section{The impacts of Brexit policies on food consumption and dietary health}

Changes in trade and production impact the relative prices of foods that in turn influence what is consumed by households. In our analysis, all individual Brexit-related policies led to reductions in food consumption (Figure 2). The reductions were greatest in the "Hard Brexit" scenario with and without agricultural subsidy form (-55 kcal/d), lowest in the "Soft Brexit" approach (-12 kcal/d), and intermediate in the "Global Britain" approach (-28 kcal/d). In contrast, combining the global and EU trade deals, with or without agricultural subsidy reform, led to an increase in food consumption compared to the no-Brexit benchmark (+10 kcal/d).

Diet composition was impacted as well. Amongst the foods reduced the most, measured by weight, were dairy (6-24 g/d, 3-13 kcal/d), fruit and vegetables (5-18 g/d, 2-8 kcal/d), and staple crops $(2-11 \mathrm{~g} / \mathrm{d}, 1-10$ $\mathrm{kcal} / \mathrm{d})$, as well as vegetable oils (0-1 g/ $\mathrm{d}, 1-10 \mathrm{kcal} / \mathrm{d})$ and red meat $(0-2 \mathrm{~g} / \mathrm{d}, 0-7 \mathrm{kcal} / \mathrm{d})$ when considering their energy content (Figure 2, Figure S2). Dairy consumption was reduced most in the agricultural-subsidy and "Hard Brexit" scenarios, whereas fruit and vegetable consumption was reduced most in the "Hard Brexit" and "Global Britain" scenarios. The "Soft Brexit" scenario led to the least 
reductions in consumption for most commodities when considering individual policies. Combining the EU trade deal of a "Soft Brexit" with global trade deals led to small increases in red meat (beef, lamb, pork) consumption, and further combination with agricultural subsidy reform mitigated the reduction in fruit and vegetable consumption.

Changes in food composition and total energy intake can affect chronic-disease incidence and mortality 13. According to our estimates, all individual Brexit-related policies were associated with net increases in diet-related mortality (Figure 3). The "Hard Brexit" scenario was associated with 4,200 additional deaths $(95 \% \mathrm{Cl}, 4,030-4,330)$ due to changes in food composition, in particular reductions in fruit and vegetable consumption, most of which stemmed from coronary heart disease and cancer (Figure S3). At the population level, the number of additional deaths was reduced by less obesity-related mortality $(-3,100$ deaths; $3,040-3,170)$ that was associated with reduced energy intake, resulting in a net increase in the burden of diet-related deaths of 1,100 (950-1,320) under a "Hard Brexit".

The Brexit-related policy approaches impacted diet and weight-related risks differently. The "Global Britain" scenario was associated with less reductions in obesity-related deaths. Together with similar increases in mortality from a lower consumption of fruits and vegetables, this led to a greater number of deaths as the "Hard Brexit" scenario $(2,480 ; 1,630-2,340)$. The "soft Brexit" scenario was associated with less increases in mortality from lower fruit and vegetable consumption, but also with less reductions in obesity-related deaths. The resulting net increase in diet-related mortality $(450 ; 410-500)$ was about half of the increase of the "Hard Brexit" scenario. The agricultural subsidy scenario mitigated some of the health impacts related to reduced fruit and vegetable consumption, but had little effect on other risk factors, including the Brexit-related reductions in obesity burden. Together, this led to the smallest net increase in diet-related mortality across the individual policy approaches $(90 ;-70$ to +250$)$.

The health impacts associated with combinations of scenarios further underlined the relative impacts of the individual scenarios (Figure 3). A combination of scenarios that included a "Global Britain" approach generally increased the detrimental health impacts as obesity reductions were either modest and increased without affecting the Brexit-related reductions in fruit and vegetable consumption. On the other hand, combining a "Soft Brexit" approach with agricultural subsidy reform mitigated most of the reductions in fruit and vegetable consumption whilst preserving some of the reductions in obesity that together resulted in a net reduction in diet-related mortality (400; 370-430).

\section{Discussion}

Brexit is expected to have significant impacts on the UK food system, which has implications for dietary risk factors and public health. The general chain of impacts leads from Brexit-related increases in trade costs to increases in prices which, all things being equal, result in reductions in consumption. Our analysis suggests that Brexit-related reductions in consumption could have two opposing effects. On the one hand, the reduced consumption of health-promoting foods, such as fruits and vegetables, is associated with significant increases in diet-related mortality. On the other hand, reduced energy intake is 
associated with reductions in mortality from obesity-related diseases. According to our analysis, the net population impact of a "Hard Brexit" would be an increase in diet-related mortality of over 1000 deaths.

The Brexit-related policy approaches had different impacts on diet-related risk factors. Negotiating new global trade agreements with the USA and Commonwealth countries increased imports and consequently energy intake, but not of the health-promoting foods responsible for most of the increases in diet-related mortality. As a result, the "Global Britain" approach was associated with a greater increase in diet-related mortality. Negotiating a trade agreement with the EU reduced, due to its trading position, both the Brexitrelated reductions in energy intake and the reductions in the consumption of health-sensitive foods. The "Soft Brexit" approach therefore resulted in a net increase in diet-related mortality that was less than half that of a "Hard Brexit" approach. Reforming agricultural subsidies such that a portion of subsidies is coupled to producing foods with beneficial health and environmental benefits led to little change in energy intake, but reduced some of the Brexit-related reductions in health-promoting foods. Combining a health-promoting subsidy reform with negotiating a new free-trade agreement with the EU mitigated most of the detrimental health impacts of Brexit and, instead of an increase, resulted in a small net reduction in diet-related mortality.

Our analysis is, to our knowledge, the first assessment of Brexit-related policy impacts on the UK food system and a comprehensive set of dietary risk factors. Our agriculture-economic analysis tracked the changes in trade, production, and final consumption of food commodities, taking into account the supplydemand relationships across all economic sectors and countries. This level of detail is particularly important for analysing changes to the UK's global trade regime. The coupling of changes in both energy intake and dietary composition allowed us to analyse the health implications for a comprehensive set of risk factors. The scope of analysis advances the current level of understanding of Brexit-related health impacts as previous studies focused primarily on changes in fruit and vegetable consumption ${ }^{7}$.

Our findings have policy implications for Brexit and other trade-related policies. The differentiated impacts that trade agreements could have on dietary composition and energy intake suggests that careful impact assessments are required to ensure trade agreements are in line with public health concerns. A too narrow focus on food prices and general food availability needs to be complemented by considering the potential changes in foods of public health importance, such as fruits and vegetables, and of weight-related risks. Trade agreements that only focus on food availability risk exacerbating the burden of overweight and obesity with detrimental impacts for public health. A two-way focus on food availability and dietary risks would benefit the design of domestic policies as exemplified by a healthsensitive reform of agricultural subsidies. Combining domestic and international policy approaches that are health-sensitive offers the best chances for improving public health whilst avoiding unintended consequences.

\section{Methods}


We used an economic-health modelling framework to estimate the potential impacts that Brexit could have on agricultural trade, food consumption, and diet-related health in the UK. The economic model consists of a computable general equilibrium (CGE) model of the global economy with a particular focus on agriculture in the EU. CGE models combine economic theory and empirical data according to which relative prices of commodities adjust so that supply matches demand across different sectors and regions. CGE models represent the whole economy, and include the agriculture sector, as well as industrial and service sectors. Due to its structure, the models allow for the identification of causal effects of policy experiments and other external factors on parameters, such as economic output per sector, inter-regional trade, and national consumption.

For this analysis, we used a computable general equilibrium model with agricultural detail, the Modular Applied General Equilibrium Tool (MAGNET), to estimate the potential impacts that changes in trade costs could have on agricultural trade, production and consumption in the UK. One of the main features of MAGNET is the comprehensive representation of land resources as a factor of production, as well as its representation of agricultural policies such as the EU's Common Agricultural Policy (CAP) and production quotas ${ }^{11}$. The price elasticities of food products that determine supply-demand reactions are in line with available meta-analyses ${ }^{17}$. Due to its specific focus, MAGNET is regularly employed to inform policy makers and other stakeholders about the economic implications of various policies and other external factors related to agriculture ${ }^{18-20}$.

Integrated into the model are projections of future socio-economic development, which allows for the analysis of economic impacts and feedback effects of policies at a medium time scale. The development trajectory to 2030 uses baseline data on trade and economic output for the year 2014 from the Global Trade Analysis Project (GTAP) and then takes into account projections of a middle-of-the-road growth path of real GDP 21 , including labour growth, and projections of biophysical yield developments of crops and pastures caused by climate and area changes. Free trade agreements that have been agreed to (e.g. between the EU and Canada) are phased in gradually. A detailed model description is provided in the Supplementary Information by Woltjer and colleagues ${ }^{11}$. Brexit was not included in the baseline, and we instead specified it as individual scenarios to isolate its impacts.

\section{Dietary risk model}

We used a national risk-disease model to estimate the impacts that dietary changes related to Brexit could have on disease mortality in the UK. The model is based on the concept of comparative risk assessment which relates changes in risk factors, such as reductions in fruit and vegetables, to changes in cause-specific mortality, such as cancer and coronary heart disease ${ }^{12}$. The same concept forms the basis of the Global Burden of Disease project that tracks the impacts of different risk factors on mortality and morbidity in different regions and globally ${ }^{5}$.

The UK-based comparative risk assessment model included eight diet and weight-related risk factors and five disease endpoints. The risk factors were high consumption of red meat, low consumption of fruits, 
vegetables, nuts, legumes, and fish, as well as being underweight, overweight, and obese, the latter of which are related to changes in energy intake. The disease endpoints were coronary heart disease (CHD), stroke, type-2 diabetes mellitus (T2DM), cancer (in aggregate and as colon and rectum cancers), and respiratory disease.

We used publicly available data sources to parameterize the comparative risk analysis. We adopted relative risk estimates that relate change in risk factors to changes in disease mortality from metaanalysis of prospective cohort studies to minimise bias from individual studies ${ }^{9,22-28}$. Age-specific mortality and population data for the UK were adopted from the Global Burden of Disease project ${ }^{14}$. Baseline data on the UK's weight distribution were adopted from a pooled analysis of population-based measurements undertaken by the NCD Risk Factor Collaboration ${ }^{29}$ and projected forward based on the statistical relationship between calorie availability and body weight ${ }^{30}$. For the uncertainty analysis, we used the low and high values of the $95 \%$ confidence intervals of the relative risk estimates. A detailed model description is provided in the Supplementary Information and by Springmann and colleagues ${ }^{31}$.

\section{Brexit-related policy scenarios}

We used the economic-health modelling framework to analyse four Brexit-related policy scenarios. The UK's default position is represented by a "Hard Brexit" scenario. In that scenario, imports from the EU and other countries with which no new trade agreement has been negotiated are subject to UK's Global Tariffs which are simplified and partly liberalised tariff lines based on the EU's Most Favoured Nations (MFN) tariffs. At the same time, the EU levies MFN tariffs on imports from the UK. For the analysis, we mapped the detailed tariff lines to the commodities represented in the model by using the Tariff Analytical and Simulation Tool for Economists (TASTE) provided by the GTAP network ${ }^{32}$. Estimates of non-tariff measures were adopted from Dhingra and colleagues ${ }^{16}$.

We constructed two scenarios that represent different ways the UK Government could approach trade. For a "Soft Brexit" scenario, we assumed the UK and the EU negotiate a free-trade agreement. In that scenario, no tariffs are applied between the UK and the EU. In addition, non-tariff measures are reduced by two thirds compared to those of a "Hard Brexit", in line with Dhingra and colleagues ${ }^{16}$. For a "Global Britain" scenario, we assumed the UK focuses primarily on negotiating new trade deals with countries other than the EU, specifically with the USA and Commonwealth countries. Mutual tariffs were reduced to zero in that scenario.

The fourth scenario focuses on domestic policy changes. As part of a "Taking back control" approach, the UK Government has announced the aim for reforming agricultural spending that within the EU is regulated by the EU's Common Agricultural Policy (CAP). In line with a "public money for public goods" approach, the intention is that a portion of subsidies will made be conditional on the delivery of public benefits such as improvements in environmental sustainability and public health. In our policy scenario on agricultural subsidy reform, we represented this intention by coupling a quarter of subsidies to the production of food commodities with beneficial health and environmental characteristics. In our model 
aggregation, we chose horticultural products (fruits, vegetables, legumes, nuts) for that purpose as those have beneficial health and environmental characteristics when compared to other foods represented in the model ${ }^{8,9}$, and increased production is in line with pathways towards healthy and sustainable food systems ${ }^{10,33}$. This choice of food group is also in line with a focus on mitigating a Brexit-related reduction in fruit and vegetable consumption.

\section{Declarations}

Both authors contributed equally to the research.

\section{References}

1. Chang, W. W. Brexit and its economic consequences. The World Economy (2018) doi:10.1111/twec.12685.

2. Sampson, T. Brexit: The Economics of International Disintegration. Journal of Economic Perspectives 31, 163-184 (2017).

3. Lang, T. \& McKee, M. Brexit poses serious threats to the availability and affordability of food in the United Kingdom. Journal of Public Health (2018) doi:10.1093/pubmed/fdy073.

4. DEFRA. Agriculture in the United Kingdom 2017. (2018).

5. Forouzanfar, M. H. et al. Global, regional, and national comparative risk assessment of 79 behavioural, environmental and occupational, and metabolic risks or clusters of risks in 188 countries, 1990-2013: a systematic analysis for the Global Burden of Disease Study 2013. The Lancet 386, 2287-2323 (2015).

6. Springmann, M. \& Freund, F. The impacts of Brexit on agricultural trade, food consumption, and dietrelated mortality in the UK. Oxford Martin School Working Paper (2018).

7. Seferidi, P. et al. Impacts of Brexit on fruit and vegetable intake and cardiovascular disease in England: a modelling study. BMJ Open 9, (2019).

8. Poore, J. \& Nemecek, T. Reducing food's environmental impacts through producers and consumers. Science 360, 987-992 (2018).

9. Bechthold, A. et al. Food groups and risk of coronary heart disease, stroke and heart failure: A systematic review and dose-response meta-analysis of prospective studies. Critical Reviews in Food Science and Nutrition 59, 1071-1090 (2019).

10. Willett, W. et al. Food in the Anthropocene: the EAT-Lancet Commission on healthy diets from sustainable food systems. The Lancet 393, 447-492 (2019).

11. Woltjer, G. B. et al. The MAGNET model: Module description. (2014).

12. Murray, C. J. L., Ezzati, M., Lopez, A. D., Rodgers, A. \& Vander Hoorn, S. Comparative quantification of health risks: conceptual framework and methodological issues. Population Health Metrics 1, 1 (2003). 
13. GBD 2017 Diet Collaborators et al. Health effects of dietary risks in 195 countries, 1990-2017: a systematic analysis for the Global Burden of Disease Study 2017. The Lancet 0, (2019).

14. GBD 2017 Causes of Death Collaborators et al. Global, regional, and national age-sex-specific mortality for 282 causes of death in 195 countries and territories, 1980-2017: a systematic analysis for the Global Burden of Disease Study 2017. The Lancet 392, 1736-1788 (2018).

15. NCD Risk Factor Collaboration. Trends in adult body-mass index in 200 countries from 1975 to 2014 : a pooled analysis of 1698 population-based measurement studies with $19 \cdot 2$ million participants. The Lancet 387, 1377-1396 (2016).

16. Dhingra, S. et al. The costs and benefits of leaving the EU: trade effects. Economic Policy 32, 651705 (2017).

17. Green, R. et al. The effect of rising food prices on food consumption: systematic review with metaregression. BMJ 346, (2013).

18. Banse, M., van Meijl, H., Tabeau, A. \& Woltjer, G. Will EU biofuel policies affect global agricultural markets? European Review of Agricultural Economics 35, 117-141 (2008).

19. Boulanger, P. \& Philippidis, G. The EU budget battle: Assessing the trade and welfare impacts of CAP budgetary reform. Food Policy 51, 119-130 (2015).

20. Helming, J. \& Tabeau, A. The economic, environmental and agricultural land use effects in the European Union of agricultural labour subsidies under the Common Agricultural Policy. Regional Environmental Change 18, 763-773 (2018).

21. Riahi, K. et al. The Shared Socioeconomic Pathways and their energy, land use, and greenhouse gas emissions implications: An overview. Global Environmental Change 42, 153-168 (2017).

22. Afshin, A., Micha, R., Khatibzadeh, S. \& Mozaffarian, D. Consumption of nuts and legumes and risk of incident ischemic heart disease, stroke, and diabetes: a systematic review and meta-analysis. Am. J. Clin. Nutr. 100, 278-288 (2014).

23. Aune, D. et al. Nut consumption and risk of cardiovascular disease, total cancer, all-cause and causespecific mortality: a systematic review and dose-response meta-analysis of prospective studies. BMC medicine 14, 207 (2016).

24. Aune, D. et al. Fruit and vegetable intake and the risk of cardiovascular disease, total cancer and allcause mortality-a systematic review and dose-response meta-analysis of prospective studies. International Journal of Epidemiology (2016).

25. Schwingshackl, L. et al. Food groups and risk of colorectal cancer. International Journal of Cancer 142, 1748-1758 (2018).

26. Schwingshackl, L. et al. Food groups and risk of type 2 diabetes mellitus: a systematic review and meta-analysis of prospective studies. European Journal of Epidemiology 32, 363-375 (2017).

27. Zheng, J. et al. Fish consumption and CHD mortality: an updated meta-analysis of seventeen cohort studies. Public Health Nutrition 15, 725-737 (2012). 
28. Global BMI Mortality Collaboration et al. Body-mass index and all-cause mortality: individualparticipant-data meta-analysis of 239 prospective studies in four continents. The Lancet 388, $776-$ 86 (2016).

29. NCD Risk Factor Collaboration (NCD-RisC). Trends in adult body-mass index in 200 countries from 1975 to 2014: a pooled analysis of 1698 population-based measurement studies with $19 \cdot 2$ million participants. The Lancet 387, 1377-1396 (2016).

30. Springmann, M., Godfray, H. C. J., Rayner, M. \& Scarborough, P. Analysis and valuation of the health and climate change cobenefits of dietary change. PNAS 113, 4146-4151 (2016).

31. Springmann, M. et al. The healthiness and sustainability of national and global food based dietary guidelines: Modelling study. The BMJ 370, 2322 (2020).

32. Horridge, M. \& Laborde, D. TASTE a program to adapt detailed trade and tariff data to GTAP-related purposes. (2010).

33. Springmann, M. et al. Health and nutritional aspects of sustainable diet strategies and their association with environmental impacts: a global modelling analysis with country-level detail. The Lancet Planetary Health 2, e451-e461 (2018).

\section{Table}

Table 1. Food trade statistics (USD million) and self-sufficiency ratio (\%) for the UK (left), and tariff measures (\%) facing the UK in the different Brexit scenarios (right).

\begin{tabular}{|c|c|c|c|c|c|c|c|c|}
\hline \multirow{2}{*}{ Food commodity } & \multicolumn{2}{|c|}{ Imports } & \multicolumn{2}{|c|}{ Exports } & \multirow{2}{*}{$\begin{array}{c}\text { Self } \\
\text { Sufficiency }\end{array}$} & \multirow{2}{*}{$\begin{array}{c}\text { UK Global } \\
\text { Tariffs }\end{array}$} & \multicolumn{2}{|c|}{ Non-Tariff Measures } \\
\hline & Total & Share EU & Total & Share EU & & & Hard Br exi1 & Soft Brexit \\
\hline Wheat & 319 & $49 \%$ & 228 & $89 \%$ & $89 \%$ & 17 & 22.58 & 7.53 \\
\hline Other grains & 688 & $42 \%$ & 430 & $89 \%$ & $82 \%$ & 4 & 22.58 & 7.53 \\
\hline Vegetables, fruits, nuts & 9,539 & $56 \%$ & 783 & $78 \%$ & $24 \%$ & 11 & 22.58 & 7.53 \\
\hline Oil seeds & 532 & $36 \%$ & 76 & $95 \%$ & $72 \%$ & 0 & 22.58 & 7.53 \\
\hline Beef & 1,323 & $92 \%$ & 683 & $84 \%$ & $71 \%$ & 42 & 22.58 & 7.53 \\
\hline Sheep \& goat meat & 418 & $19 \%$ & 588 & $91 \%$ & $108 \%$ & 47 & 22.58 & 7.53 \\
\hline Poultry & 3,803 & $83 \%$ & 618 & $73 \%$ & $75 \%$ & 17 & 22.58 & 7.53 \\
\hline Pork & 2,983 & $86 \%$ & 805 & $55 \%$ & $60 \%$ & 14 & 22.58 & 7.53 \\
\hline Vegetable oils and fats & 3,035 & $53 \%$ & 787 & $87 \%$ & $59 \%$ & 11 & 22.58 & 7.53 \\
\hline Dairy products & 4,064 & $99 \%$ & 2,403 & $76 \%$ & $86 \%$ & 33 & 22.58 & 7.53 \\
\hline Rice & 525 & $36 \%$ & 73 & $96 \%$ & $16 \%$ & 16 & 22.58 & 7.53 \\
\hline Sugar & 800 & $60 \%$ & 261 & $67 \%$ & $69 \%$ & 31 & 22.58 & 7.53 \\
\hline
\end{tabular}

\section{Figures}




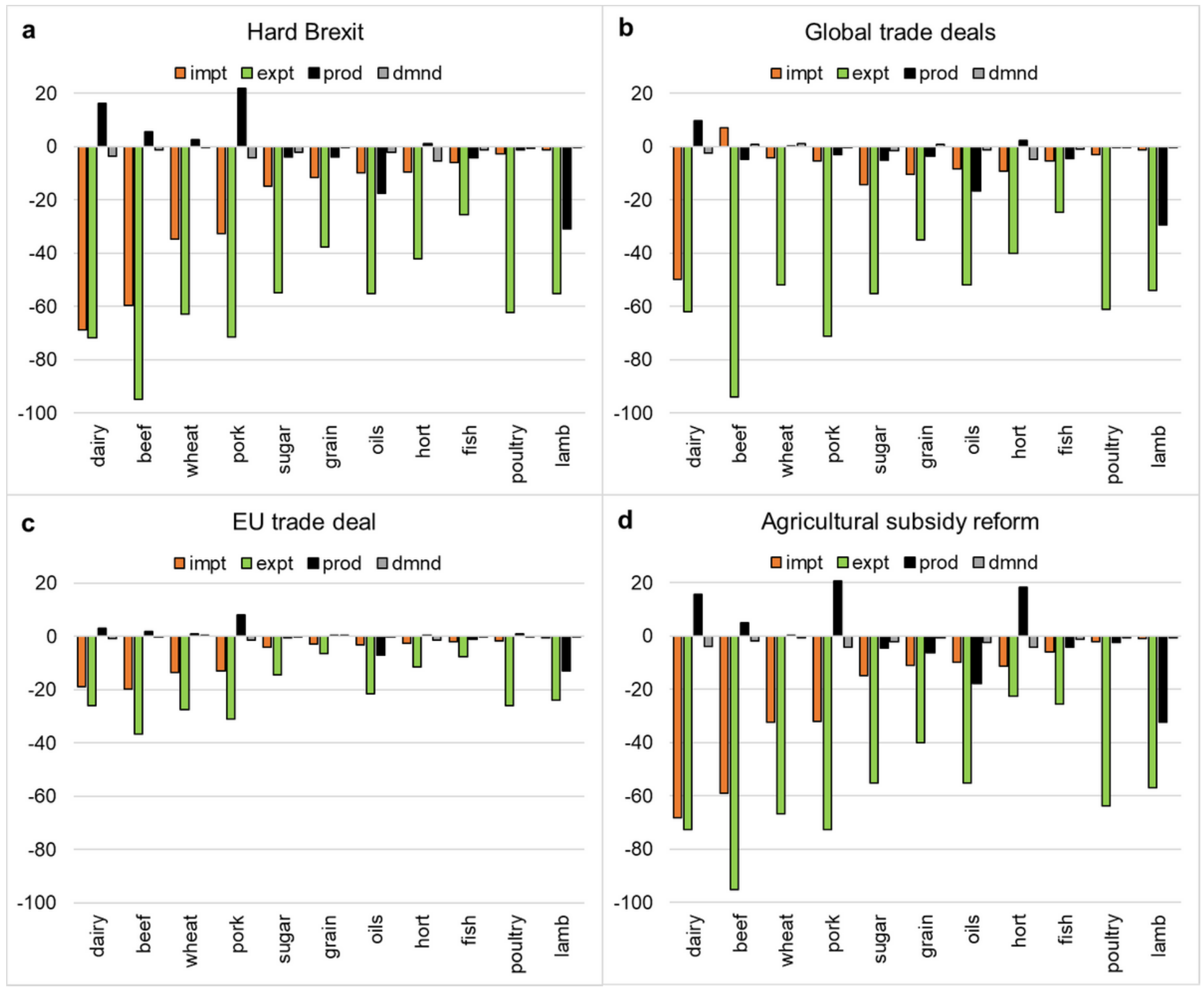

Figure 1

Percentage changes in agricultural imports, exports, production, and demand for different approaches to Brexit. The approaches include a "Hard Brexit" without additional policies (a), a Brexit with free-trade agreements with the USA and Commonwealth countries (b), a Brexit with a free-trade agreement with the EU (c), and a Brexit with a domestic reform of agricultural subsidies that incentivises the production of fruits and vegetables (d). 


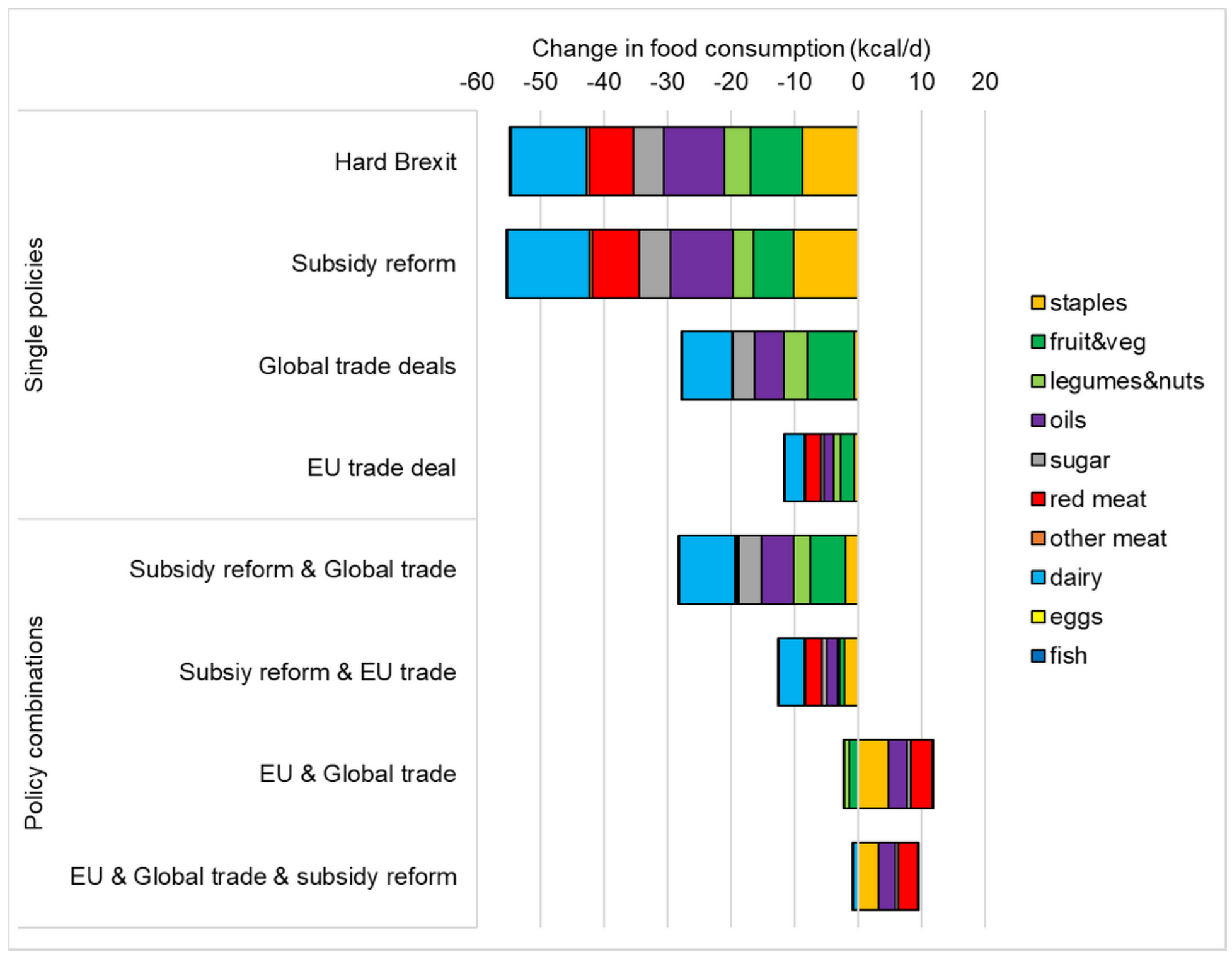

Figure 2

Change in food consumption per person $(\mathrm{kcal} / \mathrm{d})$ by food group and Brexit policy. The policies include a "Hard Brexit" without additional policies, a Brexit with agricultural subsidy reform that incentivises fruit and vegetable production, a Brexit with new global trade agreements with the USA and Commonwealth countries, a Brexit with a free-trade agreement with the $\mathrm{EU}$, and combinations thereof. 


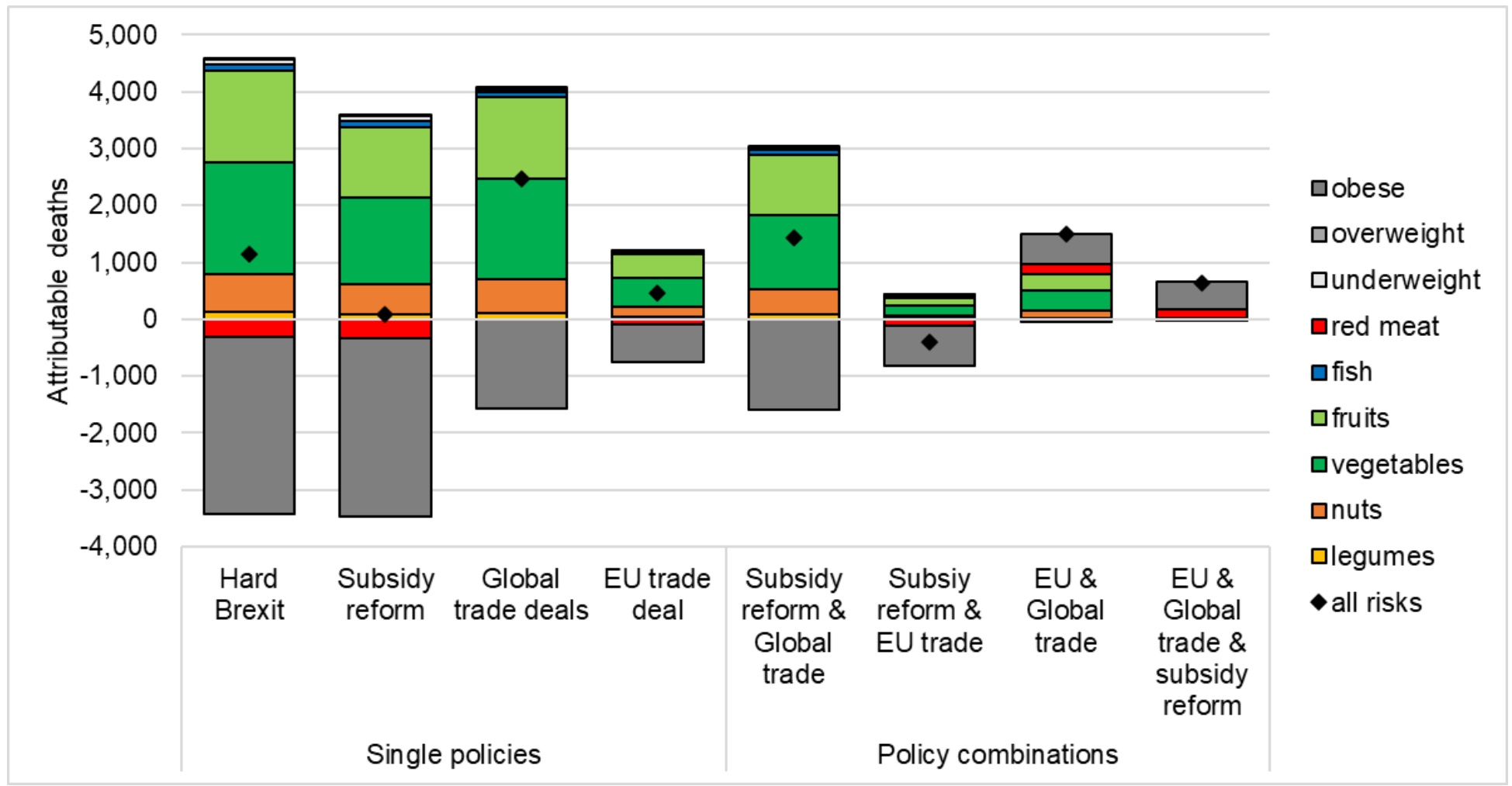

\section{Figure 3}

Number of attributable deaths by Brexit policy and risk factor. The policies include a "Hard Brexit" without additional policies, a Brexit with agricultural subsidy reform that incentivises fruit and vegetable production, a Brexit with new global trade agreements with the USA and Commonwealth countries, a Brexit with a free-trade agreement with the $\mathrm{EU}$, and combinations thereof.

\section{Supplementary Files}

This is a list of supplementary files associated with this preprint. Click to download.

- BrexitSI1214a.docx 